\title{
Terminology and nomenclature in sport and exercise medicine
}

A skilled writer should be able to explain a complex topic to a reader who is not familiar with that topic. However, that is easier said than done as every branch of science embodies its own set of terms and words. Anyone working in a specialised area has to learn the set of terms associated with that topic, and use the appropriate terms and words to communicate with their colleagues. Failure to do so creates a barrier to entry; it makes it difficult to communicate and understand what others have said about the discipline. In the early phases of a new discipline, the terminology may be used slightly differently. However, as the discipline or area of research evolves, the words and definitions used to describe the nuances of that area become standardised. This reduces the risk of ambiguity and results in the communication on the specialised topic reaching a deeper level. With well-defined terminology, the results of studies can be compared and the knowledge in that area develops at a more rapid rate.

There are many examples in sport and exercise medicine research where this has happened. Consider cricket research, where the lack of consistent definitions for injury in the sport resulted in the research on injuries plateauing. The calculation of exposure to injury varied. The sticking point was that data from different studies could not be compared. This prompted collaboration between cricket authorities in Australia, the United Kingdom, South Africa, New Zealand, the West Indies, and India to standardize the nomenclature used in cricket research. This resulted in a paper, which was widely circulated. ${ }^{[1]}$ The consensus paper went into detail about the definitions for injury, injury recovery and injury recurrence in cricket. Factors associated with exposure calculations were discussed. The paper even had worked examples showing how exposure should be calculated and a check list of information that should be collected by an injury surveillance system. It is no surprise that the quality of research into cricket injuries was transformed from being largely descriptive to more mechanistic and problem solving. This consensus paper on terminology made such an impact that it is unlikely that research will get published in high impact journals if the guidelines outlined in this paper are not adopted.

The example set by cricket was followed by soccer ${ }^{[2]}$ and then rugby $^{[3]}$. Both documents go into detail about the definitions of injury and factors to consider in calculating exposure in the respective sports. This results in studies on the incidence of injury being expressed in a comparable way. As with the research in cricket, the quality of research in soccer and cricket has increased exponentially.

Another example occurred in 2006 when the European College of Sport Science (ECSS) published its consensus statement on overtraining. ${ }^{[4]}$ This statement was prompted by the many studies that were attempting to address the consequences of overtraining, but the knowledge in the area was not progressing as it should have, because the scientists were using different terms to describe the condition. This made it difficult to compare studies. The document published by the ECSS was updated seven years later when the American College of Sports Medicine were invited to contribute. ${ }^{[5]}$ This has resulted in a set of clear descriptions and working definitions for terms in this area of research.
The attempt to improve and define terms in sport and exercise medicine research continues. Recently a paper was published which focussed on athlete proficiency. ${ }^{[6]}$ This paper provided clear definitions for athlete proficiency so that athletes can be correctly ranked into categories, instead of being loosely described as "elite" or "high level". This refining of definitions will assist researchers around the world to describe their athletes similarly; a consequence will be better quality science.

An editorial has also drawn attention to the need for clear definitions and has proposed definitions for an "athlete", age group classifications (i.e. young athletes; 12-17 years old, adult athletes; 18-35 years old, and master athletes; 35-60 years old), and level of performance. ${ }^{[7]}$ The definitions they provide are crisp and clear and easily implementable.

The establishment of definitions and methodology, and reporting standards should be adopted more widely as this contributes to better quality research. This is something that the reviewers of papers submitted to the South African Journal of Sports Medicine are going to be asked to be vigilant about, so that we can make a positive contribution to the quality of the science in sport and exercise medicine.

\section{Mike Lambert}

Editor-in-chief

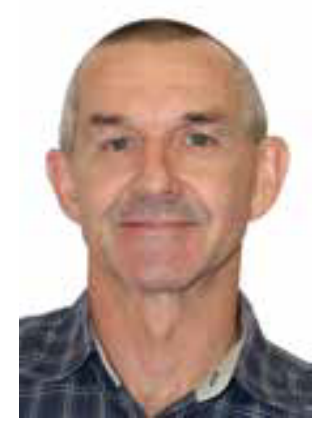

S Afr J Sports Med 2015;27(4):92.

\section{References}

1. Orchard J, Newman D, Stretch R, Frost W, Mansingh A, Leipus A. Methods for injury surveillance in international cricket. J Sci Med Sport 2005;8(1):1-14. [http:// dx.doi.org/10.1016/S1440-2440(05)80019-2]

2. Fuller C, Ekstrand J, Junge A, Andersen T, Bahr R, Dvorak J, et al. Consensus statement on injury definitions and data collection procedures in studies of football (soccer) injuries. Scand J Med Sci Sports 2006;16(2):83-92. [http://dx.doi. org/10.1111/j.1600-0838.2006.00528.x] PMID:16533346.

3. Fuller CW, Molloy MG, Bagate C, Bahr R, Brooks JHM, Donson H, et al. Consensus statement on injury definitions and data collection procedures for studies of injuries in rugby union. Br J Sports Med 2007;41(5):328-31. [http://dx.doi.org/10.1136/ bjsm.2006.033282] PMID: 17452684.

4. Meeusen R, Duclos M, Geeson M, Rietjens G, Steinacker J, Urhausen A. Prevention, diagnosis and treatment of the Overtraining Syndrome. Eur J Sport Sci 2006;6(1):14. [http://dx.doi.org/10.1080/17461390600617717]

5. Meeusen R, Duclos M, Foster C, Fry A, Gleeson M, Nieman D, et al. Prevention, diagnosis, and treatment of the overtraining syndrome: joint consensus statement of the European College of Sport Science and the American College of Sports Medicine. Med Sci Sports 2013;45(1):186-205. [http://dx.doi.org/10.1080/17461391. 2012.730061]

6. Swann C, Moran A, Piggott D. Defining elite athletes: Issues in the study of expert performance in sport psychology. Psychology of Sport and Exercise. Elsevier Ltd; 2015;16(1):3-14. [http://dx.doi.org/10.1016/j.psychsport.2014.07.004]

7. Araújo CGS, Scharhag J. Athlete: a working definition for medical and health sciences research. Scand J Med Sci Sports 2016;26(1):4-7. [http://dx.doi.org/10.1111/ sms.12632] PMID: 26750158. 